\title{
An Internal Audit of a Virtual Learning Space to Facilitate Clinical Decision-Making in Nursing
}

\author{
Beryl McEwan \\ Charles Darwin University \\ Gylo Hercelinskyj \\ University of Canberra
}

In any nursing program, it is a challenge to foster an awareness of, and engagement with, the complexity and reality of nursing practice. During their studies, nursing students have to learn the relevant underpinning theoretical knowledge for practice as well as develop their understanding of the role and responsibilities of the registered nurse in clinical settings. At a regional Australian university the Bachelor of Nursing is offered externally with the student cohort predominantly off-campus. There are significant challenges in providing opportunities to enhance learning (Henderson, Twentyman, Heel, \& Lloyd, 2006) and to foster early professional engagement with the nursing community of practice (Andrew, McGuiness, Reid, \& Corcoran, 2009; Elliot, Efron, Wright, \& Martinelli, 2003; Morales-Mann \& Kaitell, 2001) in a context for learning nursing knowledge and inter-professional collaborative practice. This paper presents the results of a series of internal audits of students' feedback of the Charles Darwin Hospital (CDU) vHospital ${ }^{\mathrm{TM}}$ undertaken from 2008 to 2010, following integration into theory and clinical nursing subjects in the Bachelor of Nursing program. The feedback from students demonstrates the value students place on teaching and learning activities that provide realistic situated learning opportunities (Hercelinskyj \& McEwan, 2011).

\section{Introduction}

tudying at university is demanding at the best of $\checkmark$ times (Andrew, McGuiness, Reid, \& Corcoran, 2009). Regardless of when students completed secondary school, they have difficulty with the change from school-based learning, adjusting to the self directed nature of learning, and becoming independent learners.

Nursing is a practice-based discipline and 
students have to be able to apply their learning in clinical settings during and after completion of their degree. Role socialisation is important to foster their understanding and appreciation of the role as well as the responsibilities and scope of nursing practice (Henderson, Twentyman, Heel \& Lloyd, 2006; Morales-Mann\& Kaitell, 2001; Tiwari, Lai, So, \& Yuen, 2006).

Charles Darwin University (CDU) is a dual sector Australian university located in the Northern Territory with over 21,000 local, national, and international students (CDU, 2011). The Bachelor of Nursing program is one of the largest programs at CDU and is delivered internally and externally. The external nature of this program means that many students do not actively connect with the University until they attend required clinical intensives on campus. As a result, their socialisation into nursing, understanding of the requirements and knowledge essential for registered nursing practice and ability to apply knowledge and concepts in a clinical setting are delayed. It also limits their appreciation of the complexities of the nursing role, particularly where they have not yet been exposed to clinical settings or where students have experience in lower level nursing roles.

\section{CDU vHospital ${ }^{\mathrm{m}}$}

To address some of these issues, a more flexible learning resource was required to enable external students to engage with nursing earlier in their program. The CDU virtual hospital project commenced in 2006 to offer a learning space where students can apply nursing knowledge and concepts to practice and reflect on nursing activities in an authentic clinical environment. The CDU vHospital ${ }^{\mathrm{TM}}$ was integrated into the program in 2008 and has since been used in first and second year subjects, including an introductory mental health subject.

The CDU vHospital ${ }^{\mathrm{TM}}$ is a cased-based online learning environment that helps students to develop critical thinking skills and the ability to make sound clinical decisions with the support and guidance of academic staff. It aims to facilitate early engagement with nursing and to foster student understanding of the role and requirements of professional nursing practice. Case-based learning was chosen in preference to problem-based learning because it better suits the large, predominantly external, student cohort and because of the constraints on staff availability and infrastructure at the University (Stjernquist \& Crang-Svalenius, 2007). Each case presented in the CDU vHospital ${ }^{\mathrm{TM}}$ reflects the diversity of the NT population and are exemplars of common health problems seen in the NT and the broader Australian context.

Cases are presented as patient stories. Like a book, students follow the patient through the various chapters representing the patient journey from admission to discharge. Each case includes text, still photos, videos and voice recordings to tell the story and students are required to complete a range of activities such as documenting assessment findings and calculating medication doses. This enables them to make clinical judgements about nursing care and to see the consequences of their actions.

Students work through each case, explore nursing problems and, apply nursing knowledge and concepts to realistic situations. Contextualising learning in this way assists students to become familiar with clinical nursing practice, facilitates the development of professional identity and fosters role socialization (Lave \& Wenger 1991). It also presents the patient in a holistic way and demonstrates how the social determinants of health can impact on an individual's well being (Andrew et al 2009; Stjernquist, \& Crang-Svalenius, 2007).

\section{Internal Audit}

Since initial integration, students have been invited to provide feedback on the CDU vHospital ${ }^{\mathrm{TM}}$ as part of ongoing quality improvement processes. This feedback has been incorporated as part of regular internal subject audits. Students also provided anecdotal feedback on the discussion boards or blogs available on the learning platform, when on campus or through phone or email conversations with academic staff. 
A review of the student responses and comments from 2008 until 2010 has identified several consistent patterns. This paper presents an overview of student feedback of the CDU vHospital ${ }^{\text {TM }}$ undertaken from 2008 to 2010 following integration into nursing subjects.

\section{The importance of learning in context}

The CDU vHospital ${ }^{\mathrm{TM}}$ has given students a context in which to develop an understanding of the reality and complexity of nursing practice. It has helped them to understand the nursing role and responsibilities and how nurses work with others in providing patient care. Students have found the visual, audio and interactive activities a welcome change from textbook learning. The cases helped them to apply theory to practice in a more engaging way than reading from a book.

this experience...was great, a look at actual processes in the hospital, it helps you understand what is involved in nursing, the team work and communication between staff members is so important (2008)

The pictures, videos and interactive exercises made the whole experience very life-like and I found that really useful. I felt as though I was dealing with a real patient and I still remember things I learned from my patient, whereas something I read in a textbook I would have to revise (2010)

Generally, students found the CDU vHospital ${ }^{\mathrm{TM}}$ a useful way to put subject content into a context that assisted their learning and understanding (Lave \& Wenger, 1991). It highlighted the complexity and reality of nursing practice in a hospital setting. Many commented on how it helped them to view the patient in a more holistic way and that applying theory to practice to a specific case better assisted their learning and understanding rather than just reading a textbook. The individual cases also assisted students to develop their critical thinking skills as they applied learned theory to specific cases. For students currently working in other nursing roles in non-hospital settings, it enabled a revision of skills and knowledge related to patient care in hospital settings.

...made me feel as though I was actually doing a unit that actually had something to do with nursing (2009)

it was a bit like being on placement because I learned to link the theory and practical elements of the unit so I could apply this to the patient (2010)

However, some found it time consuming and one student was not overly impressed with accessing yet another resource on the internet. Most students found the site accessible and, once familiar with it, easy to navigate.

\section{Feeling part of a community}

The CDU vHospital ${ }^{\mathrm{TM}}$ has also made students feel part of a nursing community of practice and through the virtual peripheral participation has fostered their role socialisation and the development of their professional nursing identity (Wenger, 1998). Students have been delighted to recognise faces when they come to campus for clinical intensives and the personal touches embedded in the resource provide students with a connection to the nursing program and, to some extent, the University.

...it was great to hear and see some faces and especially when they were faces recognised from CTB in Darwin. Felt a very close connection (2009)

....especially when my name was prompted. It gave you a feeling of inclusion not just looking into a computer and following prompts (2010)

Listerning [sic] to handover's [sic], and when my name poped [sic] in the 
system, oh my gosh! how exciting that is (2010)

\section{Preparation for clinical}

For those with little if any clinical experience, CDU vHospital ${ }^{\mathrm{TM}}$ has helped them develop some understanding of what they might experience when on clinical placement and what might be expected of them as nursing students. Students with no clinical experience were excited at being able to "visit" a hospital setting and to see what was involved in nursing.

\section{...has helped me understand my role and responsibilities as an $R N$ (2010)}

..opportunity to assess and care for the patient without having to worry about making mistakes or feeling silly because you can start over without having caused actual damage to a person or community (2010)

Many students commented on how the CDU vHospital $^{\mathrm{TM}}$ highlighted the importance of communication and teamwork between nurses and other members of the multidisciplinary team. They also became much more aware of the interaction between patients and staff and how they need to develop good communication and assessment skills to provide effective nursing care.

\section{Ease of access, usability, and navigation of the CDU vHospital ${ }^{\mathrm{m}}$}

There have been consistently negative comments about some aspects of the CDU vHospital ${ }^{\mathrm{TM}}$ such as the small page size and the way students move between pages. Most of these issues are related to the delivery platform and construction of the site and have not yet been addressed despite the consistent student feedback.

Some students were unable to access, view and/or hear some aspects, particularly the embedded videos. This was usually related to their browser, system components and their download capacity.
One student was not able to access the CDU $\mathrm{vHospital}^{\mathrm{TM}}$ at all because of intermittent satellite internet access and download capacity.

\section{Conclusion and Future Directions}

As a teaching strategy, the CDU vHospital ${ }^{\mathrm{TM}}$ has demonstrated the effectiveness of an interactive, contextual learning environment for students. It provides a safe and authentic environment in which to apply theory to practice and to prepare for clinical practice (Andrew, et al., 2009; Morales-Mann \& Kaitell, 2001; Stjernquist \& Crang-Svalenius, 2007). The feedback from the internal audit indicate that students value the CDU vHospital ${ }^{\mathrm{TM}}$ as an alternative learning resource that provides a realistic situated learning opportunity and a way to engage with the academic and professional community of nursing practice (Hercelinskyj \& McEwan, 2011). The CDU $\mathrm{vHospital}^{\mathrm{TM}}$ offers is a real opportunity to promote early engagement with nursing and the professional nursing community during their program to foster early role socialisation, development of professional identity and post-graduate role specialisation.

Issues around infrastructure and technical access continue to be problematic. Access to resources is not always equitable as we can't account for students' access to appropriate technology and/ or knowledge of or comfort in using technology. As with any electronic resource the question of long term currency and viability needs to be highlighted and addressed.

We have recently received a small internal grant to review the current cases to ensure currency of content and are planning to seek further funds to extend the current cases and develop new ones. We are planning to develop a proposal to gain funds to undertake a review of the platform and online presentation of the resource to address some of the technical and format issues consistently identified by staff and students.

One of the criticism of the CDU vHospital ${ }^{\mathrm{TM}}$ has been that is it very hospital and medical/surgical focused. In the future we hope to extend the CDU vHospital ${ }^{\mathrm{TM}}$ to include a primary health care 
centre, more cases in other clinical settings such as paediatrics or emergency care, and to develop professional development activities for currently practicing registered nurses.

\section{References}

Andrew, N., McGuiness, C., Reid, G., \& Corcoran, T. (2009). Greater than the sum of its parts: Transition into the first year of undergraduate nursing. Nurse Education in Practice, 9, 13-21.

Charles Darwin University [CDU]. (2011). Self assessment portfolio. Charles Darwin University.

Elliot, K., Efron, D., Wright, M., \& Martinelli, A. (2003). Educational technologies that integrate problem based learning principles: Do these resources enhance student learning? Presentation at the 20th Annual Conference of the Australian Society for Computers in Learning in tertiary Education. Adelaide.

Henderson, A., Twentyman, M., Heel, A., \& Lloyd, B. (2006). Students' perception of the psycho-social clinical learning environment: An evaluation of placement models. Nurse Education Today, 26, 564-571.

Hercelinskyj, G. \& McEwan, B. (2011). The Charles Darwin University vHospital: Creating an authentic virtual learning environment for undergraduate nursing students. In $\mathrm{M}$. Keppell (Ed.), Physical and virtual learning spaces in higher education. Hershey, PA. IGI Global.

Lave, J. \& Wenger, E. (1991). Situated learning: Legitimate peripheral participation. Cambridge: Cambridge University Press.

Morales-Mann, E.T. \& Kaitell, C.A. (2001). Problem-based learning in a new Canadian curriculum. Journal of Advanced Nursing, 33(1), 13-19.

Stjernquist, M. \& Crang-Svalenius, E. (2007). Problem based learning and the case methodmedical students change preferences during clerkship. Medical Teacher, 29, 814-820.

Tiwari, A., Lai, P., So, M., \& Yuen, K. (2006). A comparison of the effects of problem-based learning and lecturing on the development of students' critical thinking Medical Education, 40(6), 547-554.

Wenger, E. (1998). Communities of practice: Learning, meaning and identity. Cambridge: Cambridge University Press.

\section{Biographies}

Beryl McEwan is a lecturer and Ph.D. candidate in nursing at Charles Darwin University. Her research and academic interests include nursing as a community of practice; role socialization, transition, and development of professional identity in nursing; and flexible and virtual teaching and learning in higher education.

Gylo Hercelinskyj (Ph.D.) was the academic coordinator of the CDU vHospital ${ }^{\mathrm{TM}}$ from 20082011 at Charles Darwin University. She is now Assistant Professor at the University of Canberra. Her research and academic interests include professional identity and role socialisation in nursing, online and virtual learning and teaching in higher education, and intercultural competence in nursing education. 